\title{
Dynamic Failure Analysis of Concrete Dams under Air Blast
}

\author{
[Farhoud Kalateh $]^{1}$
}

\begin{abstract}
In present study, the air blast response of the concrete dams including dam-reservoir interaction and acoustic cavitation in the reservoir is investigated. The finite element (FE) developed code are used to build three dimensional (3D) finite element models of concrete dams. A fully coupled Euler-Lagrange formulation has been adopted herein. Zhou et al, [1] model including the strain rate effect is employed to model the concrete material behavior subjected to blast loading. In addition, a onefluid cavitating model is employed for the simulation of acoustic cavitation in the fluid domain. A parametric study is conducted to evaluate the effects of the air blast loading on the response of concrete dam systems. Hence, the analyses are performed for different heights of dam and different values of the charge distance from the charge center. Numerical results revealed that (1) concrete arch dams are more vulnerable to air blast loading than concrete gravity dams; (2) reservoir has mitigation effect on the response of concrete dams; (3) acoustic cavitation intensify crest displacement of concrete dams.
\end{abstract}

Keywords-Air blast loading; concrete dams; finite element method; dam-reservoir interaction; acoustic cavitation, concrete damage model

\section{Introduction}

Over the last two decades, the use of explosives by terrorist groups around the world that target civilian buildings and other structures is becoming a growing problem and has resulted in considerable attention which has been raised on the behavior of engineering structures under blast or impact loading. However, blast response of many important civil infrastructures has not yet been well understood as a result of the complexities in their material behavior, loading and higher nonlinearities. Concrete dams which are indivisible parts of any society are an example of such important civil infrastructure used for storage of water, generation of electricity etc. Blast loading on concrete dams may result in disaster due to water crisis, consequent flood flows and related damage events. Hence, understanding the dynamic behavior of concrete dams under blast loading through numerical simulations is of utmost importance. Therefore, the study of the effects of blast loading on structures has been a field of active research over the last decade $[2,3]$.

1) Farhoud Kalateh /Assistant Professor (Author)

University of Tabriz

Iran
In the current research, different parameters affecting the nonlinear response of concrete dams and their mathematical representation are explained. The major contribution in this research are considering development of cavitating region in the reservoir that induced nonlinear behavior of water and implementing a strain rate dependent material law for concrete in the material nonlinearity analysis of dam body. Additionally, a detailed study is performed for the evaluation of performance of gravity and arch concrete dams. The dynamic response of the dams subjected to air blast loading is carried out for different dam height ranging from 50 to $150 \mathrm{~m}$ and 100 to $250 \mathrm{~m}$ for gravity and arch dams respectively. The influence of dam height, standoff distance and reservoir cavitating on the performance of the concrete dams is also investigated. All numerical simulations are carried out based on the developed FORTRAN finite element code. A fully coupled numerical approach with combined Lagrangian and Eulerian methods, in which the reservoir are modeled using an Eulerian mesh, while the dam concrete is modeled using a Lagrangian mesh, is adopted to permit for the incorporation of the essential processes, namely the air blast loading, fluidstructure interaction, acoustic cavitation in the reservoir and nonlinear structural response. In the developed code, an iterative partitioned implicit scheme which is used to time integration of dynamic nonlinear equilibrium equations of fluid and structure domains and Element-by-Element PCG solver together with diagonal preconditioning are used to solve the large equation system resulting from the finite element discretization of the governing equations of fluid and structure domains. Fig.1 provides the sketch of the involved domains and boundary conditions of the finite element model. It is observed in Fig. 1 that the outer surface of the fluid domain is set to be a non-reflecting boundary.

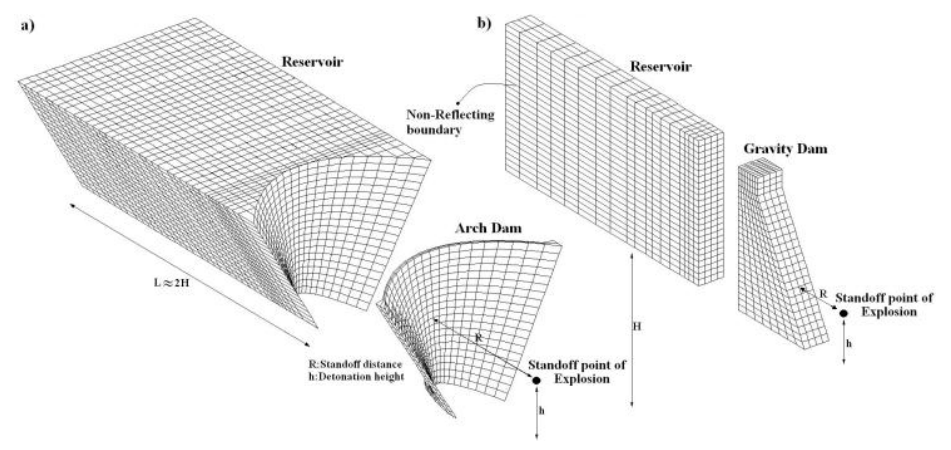

Figure 1. Concrete dam-reservoir finite element model subjected to air blast loading a) Arch dam -reservoir b) Gravity dam- reservoir 


\section{Air blast}

Air blast which involves the detonation of explosive material in air can be modeled with a decaying exponential equation form that uses a series of parameters, and rely on explosive charge size, type and standoff point. Many different sets of air blast parameter data in both graphical and equation form are available in the literature [4-7]. Thus the objectives of this section is to describe blast parameters definitions from the open literature and implement these in a load generation code to produce air blast loading for finite element simulation of dams structures subjected to explosive air burst. The evolution of an air blast involves several stages: detonation, shock wave formation and propagation and decay in the shock wave strength that terminate with a return to ambient conditions. Fig. 2 illustrates a schematic diagram of a typical time history of overpressure at a stationary location affected by an explosion in air.

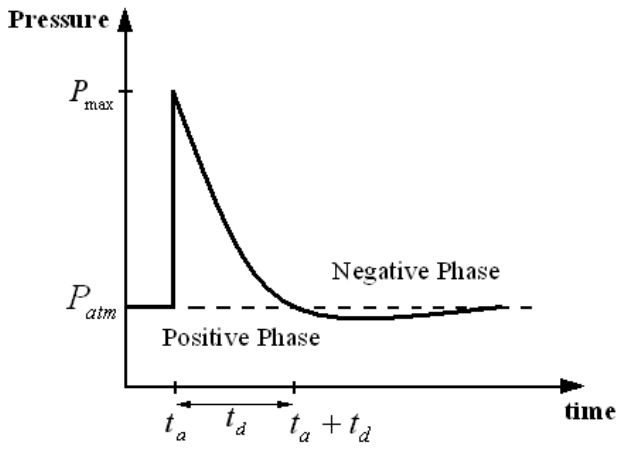

Figure 2. Schematic of a typical air blast profile

\section{Structural equations}

The second order equations of motion for solid can be written as

$$
\nabla \cdot \sigma+\boldsymbol{f}_{s}^{e x t}=\boldsymbol{\rho}_{s} \frac{\partial^{2} \boldsymbol{u}}{\partial \boldsymbol{t}^{2}}
$$

where $u$ corresponds to the displacement of the structure, $\sigma$ is the structural stress tensor, refers to solid density and is the load vector due to the external structural loads. The equations of motion for solid (Eq. (1)) is written in the most general form, which could include both material and geometric nonlinearities. Using standard procedures for finite element discretization of the structural domain, the equations of motion for the structure subjected to external blast forces may be written in standard finite element form as

$$
[M]\{\ddot{u}\}+[C]\{\dot{u}\}+\int B^{T} \sigma d \Omega=\left\{F_{a}\right\}+\left\{F_{s}\right\}
$$

In which, $[\boldsymbol{M}],[\boldsymbol{C}]$ the structural mass matrix, damping matrix, is $\boldsymbol{B}$ displacement -strain related matrix and $\boldsymbol{\sigma}$ is tensor of internal stresses of structure respectively. $\{\boldsymbol{u}\}$ is the vector of nodal displacements relative to the ground, $\left\{\boldsymbol{F}_{a}\right\}$ and $\left\{\boldsymbol{F}_{s}\right\}$ is the vector of forces associated with the air blast loading and hydrodynamic pressure produced by fluid domain, respectively.

\section{Fluid equations}

The set of governing equations, which describes the fluid domain in Cartesian coordinates, are the Euler equations where the viscosity, thermal conductivity, surface tension and turbulence are generally ignored. As the liquid and cavitating fluid are assumed to be compressible and barotropic in this work, total energy equation is not required to be solved directly. The dynamic equation of reservoir domain can be presented with some manipulation as follow

$\nabla^{2} p=\frac{1}{c(p)^{2}} \frac{\partial^{2} p}{\partial t^{2}}$

Where $c(p)$ is pressure dependent acoustic wave velocity, $p$ is hydrodynamic pressure. The Finite element discretize form of Eq. (11) can be written as follow

$[\boldsymbol{G}(\boldsymbol{p})] \cdot \ddot{\boldsymbol{p}}+[\boldsymbol{D}(\boldsymbol{p})] \cdot \dot{\boldsymbol{p}}+[\boldsymbol{H}] \cdot \boldsymbol{p}=-\rho \cdot[\boldsymbol{Q}]^{T} \ddot{\boldsymbol{u}}+\left\{\boldsymbol{F}_{f}\right\}$

Here, $\left[\boldsymbol{G}_{i j}\right]=\sum \boldsymbol{G}_{i j}^{e},\left[\boldsymbol{D}_{i j}\right]=\sum \boldsymbol{D}_{i j}^{e}$ and $\left[\boldsymbol{H}_{i j}\right]=\sum \boldsymbol{H}_{i j}^{e}$ are matrices representing the mass, damping and stiffness matrix of the fluid domain, respectively. $\left\{\boldsymbol{F}_{f}\right\}=\sum\left\{\boldsymbol{F}_{\left.\text {body } \text { Fre }_{\text {e }}\right\}_{i}}\right.$ is external body force of fluid domain and $\left[\boldsymbol{Q}_{i j}\right]=\sum \boldsymbol{Q}_{i j}^{e}$ is the total coupling matrix. $\ddot{u}$ is acceleration along interface.

\section{v. Nonlinear fluid-structure coupling scheme}

The coupling between the fluid and structure domains is applied through the forcing terms. Since have been already assumed the fluid to be inviscid, the coupling occurs only in the normal direction.

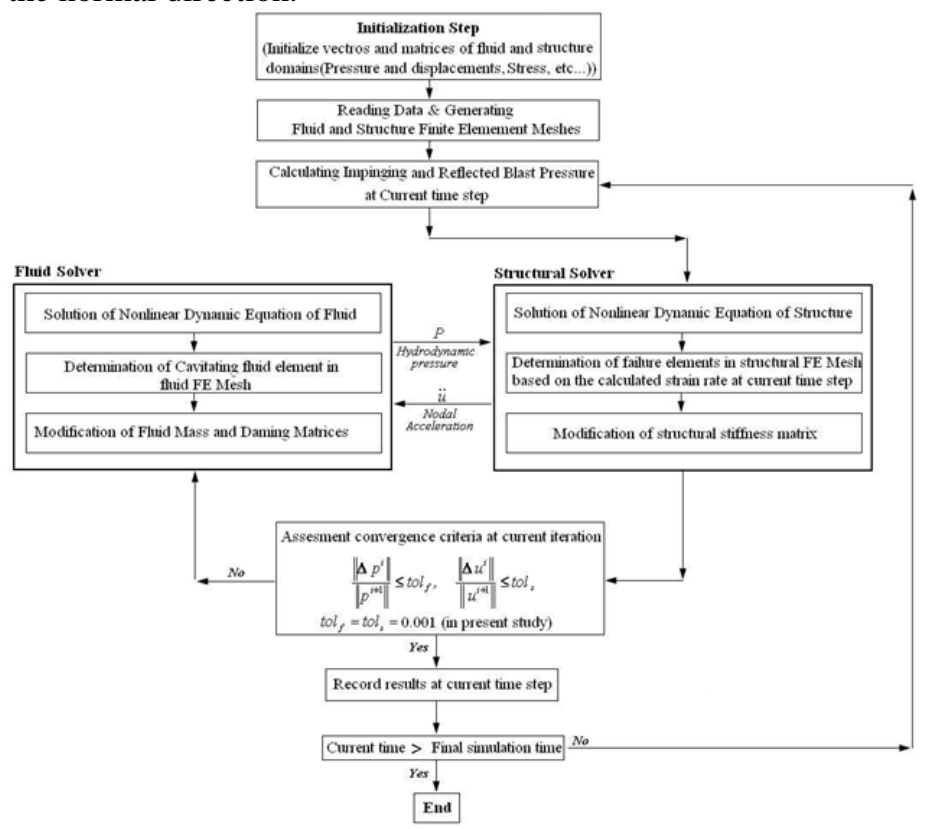

Figure 3. Flow chart of solution algorithm 
Proc. of the Sixth International Conference on Advances in Civil, Structural and Environmental Engineering - ACSEE 2017. Copyright $(\odot$ Institute of Research Engineers and Doctors. All rights reserved.

ISBN: 978-1-63248-139-9 doi: 10.15224/ 978-1-63248-139-9-20

Eqs. (2) and (4) describe the nonlinear finite element discretized equations for the dam-reservoir interaction problem. The solution of this system is obtained by using a partitioned iterative strategy, which is implemented by means of a predictor-multicorrector scheme applied at each time step.Solution algorithm is summarized in Figure (2).

\section{vI. Example and Numerical Simulation}

In this study, Morrow point arch concrete arch dam is selected as representative concrete arch dams in order to study the effect of air blast on the dynamic performance of concrete dams. The Morrow point arch dam on the Gunnison River located in Colorado with a height of $143 \mathrm{~m}$. The finite element model of Morrow point arch dam is presented in Figure 4. Material of the dams is assumed to be nonlinear viscoplastic, isotropic and homogeneous. The water is assumed to be nonlinear acoustic due to cavitation. Fluid and structure are modeled using eight node and twenty node hexahedron elements, respectively. In fluid domain, mesh is truncated at non-reflecting boundary. Physical parameters chosen for the system are as follows:

For the dam concrete: $E_{c}=34.3 \times 10^{9} \mathrm{~Pa} \quad, v_{c}=0.2$. For the reservoir water: $c=1439 \mathrm{~m} / \mathrm{s}$ and $\rho_{w}=1019 \mathrm{~kg} / \mathrm{m}^{3}$.It should be noted that reservoir is full in the different considered models and the water level in the reservoir, is assumed equal to the crest of dam in the finite element models.
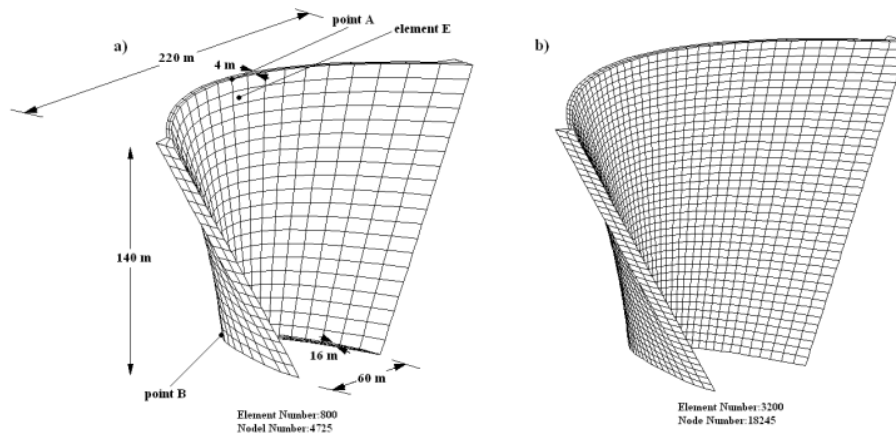

Figure 4. Finite element model of concrete arch dam and relevant dimensions and arrangement of target points and target element a) coarse mesh b) refined mesh

\section{A. Concrete arch dam: Morrow point arch dam air blast response}

The interest in this example is directed towards application of the proposed method for the evaluation of response of arch dams under blast loading. The benchmark problem is morrow point arch dam. Morrow point dam depicted in Figure 4, is a double curved arch dam chosen for bench mark problem in the present study. Although it has a height of $142 \mathrm{~m}$, but it has been assumed four different heights of $100 \mathrm{~m}, 150 \mathrm{~m}, 200 \mathrm{~m}$, and $250 \mathrm{~m}$ in order to study the effect of the dam height on the blast loading behavior of concrete arch dams.
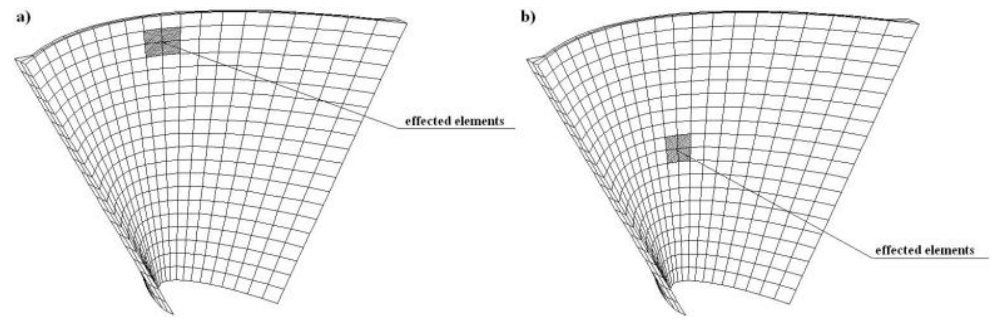

Figure 5. Affected zone of concrete arch dam by air blast loading a) upper part b) middle part

As shown in Figure 5 two different location for charge is assumed, one is in the upper part of dam close to crest and the other is in the middle of dam. Figure 4 shows coarse and refined 3D Finite Element model of coupled system along with its relevant dimensions. It has been employed 13360, 8node fluid element in the model of reservoir and 800, 20-node brick element for discretization of dam structure in the coarse FE model and 49600, 8-node fluid element in the model of reservoir and 3200, 20-node brick element for discretization of arch dam structure in the refined mesh.

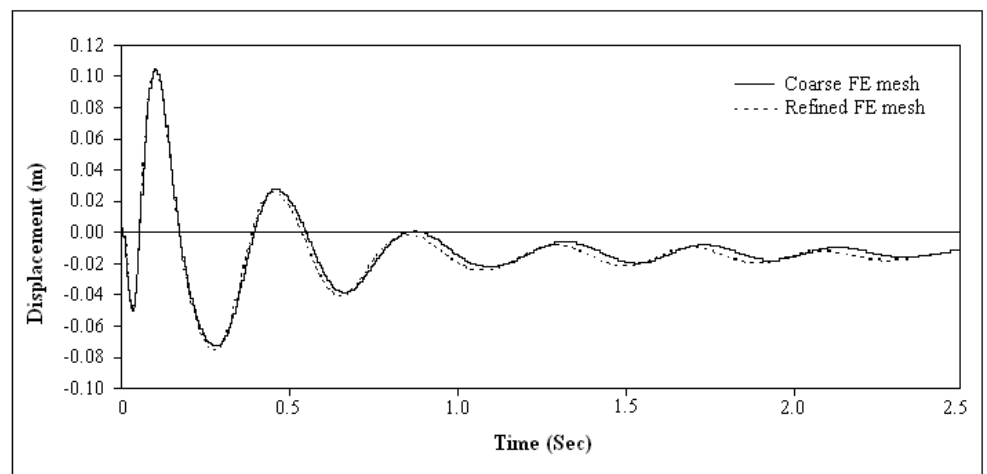

Figure 6. Comparison of Morrow point concrete arch dam crest displacement time history subjected to air blast loading for coarse and refined FE meshes.

Figure 6 illustrates the response of morrow point arch dam in the first 2.5 seconds of applied air blast loading at the upper part of the arch dam that is evaluated using coarse and refined FE meshes. Time history graphs of the displacement of point A, which is located at the crest of dam, were depicted in Figure 20 for different standoff points. For height of $250 \mathrm{~m}$, standoff point coordinate is $(R=10 m, h=235 \mathrm{~m})$, for height of $200 \mathrm{~m}$, standoff coordinate is $(R=10 \mathrm{~m}, h=185 \mathrm{~m})$, for height of $150 \mathrm{~m}$ standoff point coordinate is $(R=10 \mathrm{~m}, h=135 \mathrm{~m})$ and for height of $100 \mathrm{~m}$, standoff point coordinate is $(R=10 \mathrm{~m}, h=86 \mathrm{~m})$. It can be observed from Figure 7 that the maximum displacement of the crest of arch dam for height of $250 \mathrm{~m}$ is $12.4 \mathrm{~cm}$ toward upstream face of dam with considering cavitation, but crest displacement attained $10.5 \mathrm{~cm}$ without considering cavitation which shows an $18.1 \%$ increase of displacement due to bulk cavitation forming in the reservoir. Cavitation has significant effects on response of 
Proc. of the Sixth International Conference on Advances in Civil, Structural and Environmental Engineering - ACSEE 2017. Copyright $(\odot$ Institute of Research Engineers and Doctors. All rights reserved.

ISBN: 978-1-63248-139-9 doi: 10.15224/ 978-1-63248-139-9-20

high arch dams, and as for heights of $200 \mathrm{~m}, 150 \mathrm{~m}$ and 100 $\mathrm{m}$, crest displacement increase were $15.5 \%, 11.5 \%$ and $15 \%$, respectively. But in all, cavitation effects decrease with decrease of dam height.
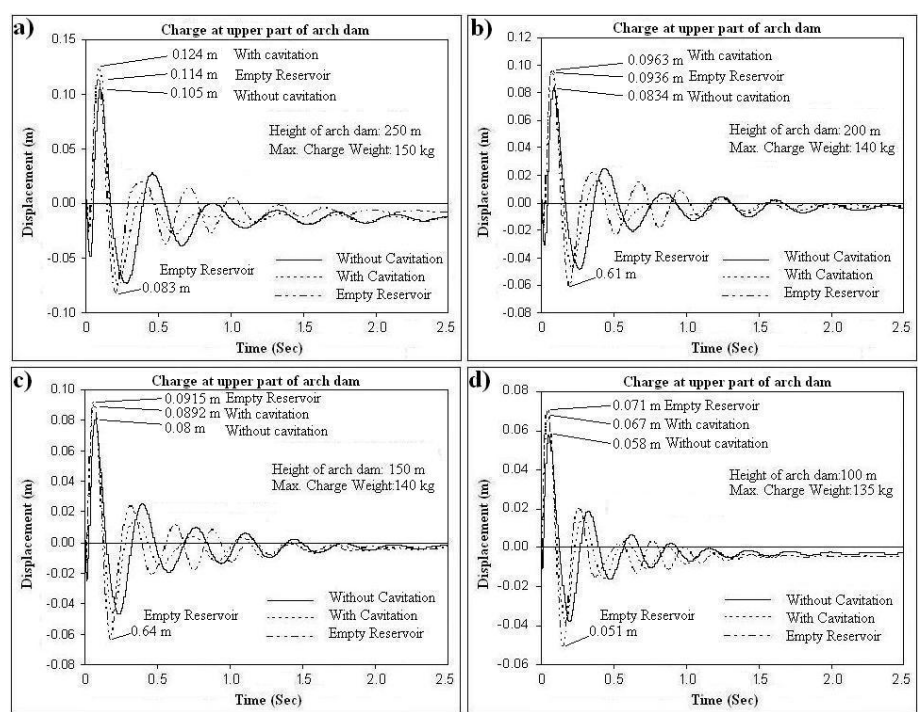

Figure 7. Crest displacement time histories at the point A for different dam heights subjected to air blast located at the upper part of downstream face of arch dam: a) $\mathrm{H}=250 \mathrm{~m}$; b) $\mathrm{H}=200 \mathrm{~m}$; c) $\mathrm{H}=150 \mathrm{~m}$; d) $\mathrm{H}=100 \mathrm{~m}$

The reason is that the cavitating region adjacent to upstream face of high arch dam expanded violently and as a result, the collapsing of this region induced larger reloading on dam structure. Other aspect that is studied in Figure 7 is the reservoir effects on the coupled system performance that arch dam reservoir systems analyses with full reservoir and empty reservoir. Obtained results revealed that reservoir reduces the maximum crest displacement of dam, and as for arch dam heights of $250 \mathrm{~m}, 200 \mathrm{~m}, 150 \mathrm{~m}$ and $100 \mathrm{~m}$, the crest displacement decrease are $7.9 \%, 10.9 \%, 12.5 \%$ and $18.3 \%$, respectively. Reduction effect of reservoir on arch dam dynamic response increases with decreasing of arch dam height which is contrary to concrete gravity dam behavior. As shown in Figure 7, the maximum charge weight located close to crest of arch dam that resulted in the collapse of the dam decrease with reduction of dam height, and as for dam heights of $250 \mathrm{~m}, 200 \mathrm{~m}, 150 \mathrm{~m}$ and $100 \mathrm{~m}$, the maximum charge weight is computed as $150 \mathrm{~kg}, 140 \mathrm{~kg}, 140 \mathrm{~kg}$ and $135 \mathrm{~kg}$, respectively. The maximum charge weight for arch dam decreases very smoothly with decreasing of height of dam. The damaged element of arch dam in downstream and upstream face of dam body for $150 \mathrm{~kg}, 140 \mathrm{~kg}, 140 \mathrm{~kg}$ and $135 \mathrm{~kg}$ TNT charge for dam heights $\mathrm{H}=250 \mathrm{~m}, \mathrm{H}=200 \mathrm{~m}$, $\mathrm{H}=150 \mathrm{~m}$ and $\mathrm{H}=100 \mathrm{~m}$, respectively and with standoff distance $10 \mathrm{~m}$ and standoff height are shown in Figure 8. As detonation occur close to upper part of dam crest, damaged elements propagates at the center of arch dam body close to dam crest. With decrease of arch dam height, the pattern of damage is changed and failure elements gradually propagate along the dam crest and damaged zone is extended. Figure 9 shows time history diagrams of the crest displacement of the arch dam corresponding to the point A for different dam heights and for charge located at the middle of arch dam.

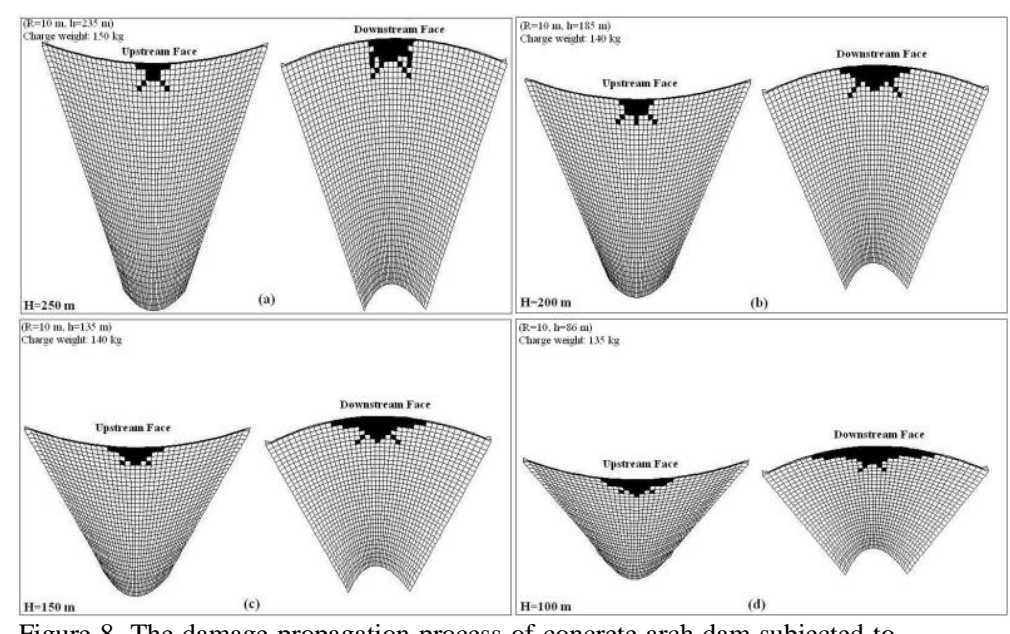

Figure 8. The damage propagation process of concrete arch dam subjected to air blast loading close to upper part of downstream face of dam for different height of dam, a) $\mathrm{H}=250 \mathrm{~m}, \mathrm{~b}) \mathrm{H}=200 \mathrm{~m}, \mathrm{c}) \mathrm{H}=150 \mathrm{~m}, \mathrm{~d}) \mathrm{H}=100 \mathrm{~m}$
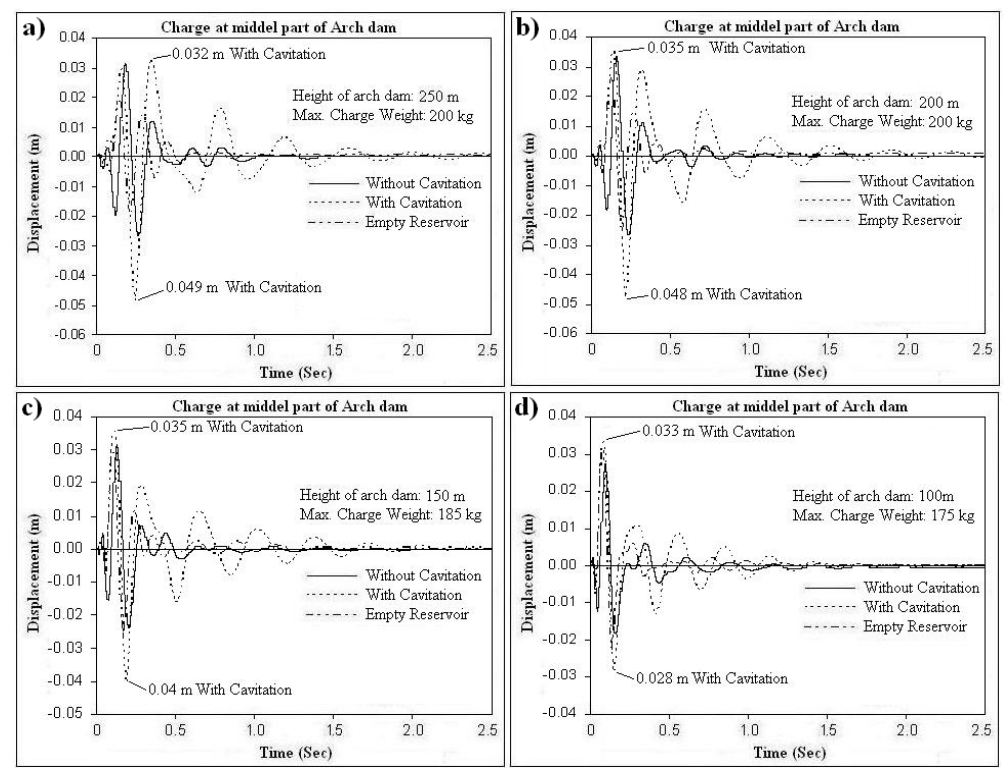

Figure 9. Crest displacement time histories at the point $\mathrm{A}$ for different dam heights subjected to air blast located at the middle part of downstream face of arch dam: a) $\mathrm{H}=250 \mathrm{~m}$; b) $\mathrm{H}=200 \mathrm{~m}$; c) $\mathrm{H}=150 \mathrm{~m}$; d) $\mathrm{H}=100 \mathrm{~m}$

Consequently, for dam height of $250 \mathrm{~m}$, standoff point coordinate is $(R=10 \mathrm{~m}, h=130 \mathrm{~m})$, for dam height of $200 \mathrm{~m}$, standoff point coordinate is $(R=10 m, h=108 \mathrm{~m})$, for dam height of $150 \mathrm{~m}$, standoff point coordinate is $(R=10 \mathrm{~m}, h=80 \mathrm{~m})$ and for dam height of $100 \mathrm{~m}$, standoff point coordinate is $(R=10 \mathrm{~m}, h=48 \mathrm{~m})$. As illustrated in Figure 9, the displacement of dam crest pattern obtains different from in Figure 7 and cavitation totally changes the crest displacement manner and intensifies the crest displacement. This is for the complicated nature of arch dam reservoir system and interaction between different domains. It can be seen from Figure 9 that the maximum displacement of 
the crest of arch dam for dam height $250 \mathrm{~m}$ is $4.9 \mathrm{~cm}$, for dam height $200 \mathrm{~m}$ is $4.8 \mathrm{~cm}$ and for dam height $150 \mathrm{~m}$ is $4 \mathrm{~cm}$ toward downstream face of dam with considering cavitation and for dam height $100 \mathrm{~m}$ the maximum crest displacement obtain $3.3 \mathrm{~cm}$ toward upstream face of dam with considering cavitation. The reason is that with increase of dam height, collapsing of cavitating regions and consequent reloading when structure reverse direction, create larger peak in displacement response that intensify crest displacement in the downstream direction. As presented in Figure 9, the maximum charge weight located close to the middle of arch dam that resulted in collapse of dam decreases with reduction of dam height, and as for dam heights of $250 \mathrm{~m}, 200 \mathrm{~m}, 150 \mathrm{~m}$ and $100 \mathrm{~m}$ the maximum charge weights computed are $200 \mathrm{~kg}$, $200 \mathrm{~kg}, 185 \mathrm{~kg}$ and $175 \mathrm{~kg}$, respectively. The damaged element of arch dam in downstream and upstream face of dam body for $200 \mathrm{~kg}, 200 \mathrm{~kg}, 185 \mathrm{~kg}$ and $175 \mathrm{~kg}$ TNT charge for dam heights $\mathrm{H}=250 \mathrm{~m}, \mathrm{H}=200 \mathrm{~m}, \mathrm{H}=150 \mathrm{~m}$ and $\mathrm{H}=100 \mathrm{~m}$, respectively and with standoff distance $10 \mathrm{~m}$ and standoff height are shown in Figure 10. As shown in Figure 10, the blast pressure generated from air blast loading causes a highly localized damage close to the middle part of downstream face of dam body facing the explosion center and causes a confined damage zone in the downstream face of dam close to abutments. The crack damage in the upstream face, near the bank of dam, extends due to tensile stress arise from blast loading and the lower tensile strength of concrete material than its compressive strength.

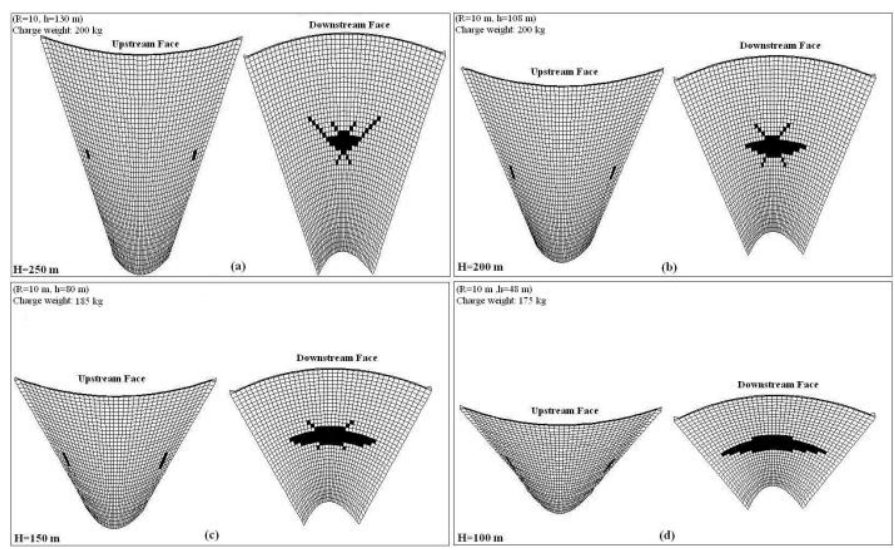

Figure 10. The damage propagation process of concrete arch dam subjected to air blast loading close to middle part of downstream face of dam for different height of dam, a) $\mathrm{H}=250 \mathrm{~m}, \mathrm{~b}) \mathrm{H}=200 \mathrm{~m}, \mathrm{c}) \mathrm{H}=150 \mathrm{~m}, \mathrm{~d}) \mathrm{H}=100 \mathrm{~m}$

\section{Conclusion}

In the present study, the three dimensional finite element developed Fortran code has been used to investigate the effect of air blast loading on concrete dams and analysis procedure is done for typical concrete gravity dam and concrete arch dam with different heights and different standoff point of charge with empty and full reservoirs. In addition, bulk cavitation effects on response of concrete dams were studied. The following is a brief outline of the key results obtained from this study:
1) Arch dam with changing charge location close to the middle part of the dam, the response scheme of the arch dam changed completely.

2) Charge weight that led to collapse of both types of concrete dams increases with increasing height of concrete dams. This indicated that concrete arch dams are more vulnerable to air blast loading.

3) The inclusion of reservoir in the numerical model decreases the response of concrete dams under air blast. For arch dam, increase in the height of dam decreases reduction effect of reservoir. Maximum reduction effect of reservoir is approximately $18 \%$ for both types of concrete dams.

4) Acoustic cavitation increases the response of concrete dams under blast loading. As cavitation intensifies crest displacement of concrete arch dam at the maximum of $15.5 \%$.

\section{References}

[1] Zhou X. Q., Hao H., Deeks A.J. Modelling dynamic damage of concrete slab under blast loading. In: Hao H, Lok TS, Gu GX, editors. Proceedings of the sixth international conference on shock and impact loads on structures, Perth, Australia, 7-9 December 2005:703-10. ISBN: 9810535503

[2] Ngo T., Mendis P., Gupta A., Ramsay J. Blast loading and blast effects on structures - an overview. EJSE special issue: loading on structures. Australia: The University of Melbourne; 2007.

[3] Remennikov A. M. A review of methods for predicting bomb blast effects on buildings. Journal of Battlefield Technology, 2003, 6(3):5-10.

[4] Guzas E. L., Earls C. J. Air blast load generation for simulating structural response. Steel and Composite Structures, 2010, (10): 429-455

[5] Baker W.E. Explosions in Air. University of Texas Press, Austin, 1973.

[6] Baker W. E., Cox P., Westine P. S., Kulesz J. J. and Strehlow R.A. Explosion hazards and evaluation. Elsevier, New York, 1983.

[7] Kinney G.F. , Graham K.J. Explosive Shock in air. Springer-Verlag, New York, 2nd edition, 1985.

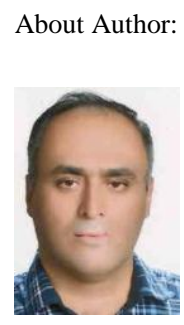

Farhoud Kalateh received a B.S. degree in 1997 from Tabriz University, a M.S. degree in Hydraulic Engineering from Tehran University in 1999, and a Ph.D. degree in the field of Hydraulic Engineering from the University of Tehran in 2011. In 2011, he joined the Department of Civil and Environmental Engineering at University of Tabriz, Iran, where he is currently Assistant Professor. $\mathrm{He}$ has studied a variety of Hydraulic structural Engineering subjects; however, his research interests include numerical modeling of dam's behavior, nonlinear dynamic analysis, fluid-structure interaction, soil-structure interaction, blast response of hydraulic structures and probabilistic dynamic analysis of hydraulic structures. He is also author or co-author of some publications. 